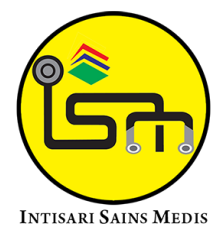

Published by Intisari Sains Medis

\title{
Gelombang Brainstem Evoked Response Audiometry (BERA) pada anak di bawah lima tahun dengan keterlambatan bicara dan bahasa disertai gangguan pendengaran di RSUP Sanglah, Bali, Indonesia
}

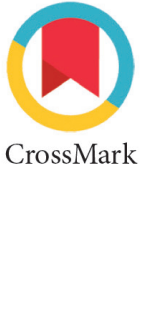

Ni Made Ary Wisma Dewi ${ }^{*}$, I Made Wiranadha ${ }^{1}$

\section{ABSTRACT}

Background: Hearing loss is one factor that influences speech and language development in children, especially in the first five years of life. The detection of hearing loss in a child can be done with an objective Brainstem Evoked Response Audiometry (BERA). This study aims to evaluate the value of BERA waves in children under five with speech and language delays at the ENT outpatient clinic of Sanglah General Hospital Denpasar.

Methods: This study is a retrospective descriptive study design by taking secondary data from the medical records of patients with speech and language delays accompanied by hearing loss who were subjected to BERA examination. Samples were taken by consecutive sampling. Data analysis in this study consisted of descriptive statistical analysis, independent $T$ test, and one-way ANOVA. Data were analyzed using SPSS version 24 for Windows.
Results: This study involved 65 people as a sample. Based on gender, it was found that male (76.9\%) was more than female (23.1\%). Most of them were aged 24-35 months (43.1\%). The most hearing loss was Moderate SNHL on the right ear (38.5\%), while Mild SNHL on the left ear (38.5\%). The mean latency time between I-V waves in the left ear of boys was longer, that was $4.96 \mathrm{~ms}$ with a variation of $0.56 \mathrm{~ms}$, compared to $4.59 \mathrm{~ms}$ for girls with a deviation of $0.64 \mathrm{~ms}$. There was a significant difference in the mean latency between waves I-V of the left ear between male and female toddlers ( $p=0.033$ ).

Conclusion: Based on the research, it was found that the absolute latency time and between waves of BERA on the right ear did not have a significant difference in boys and girls, but on the left ear, there was a statistically significant difference in the mean of latency time between waves IV in boys and girls.

Keywords: BERA, Hearing Loss, Speech, Language.

Cite This Article: Dewi, N.M.A.W., Wiranadha, I.M. 2021. Gelombang Brainstem Evoked Response Audiometry (BERA) pada anak di bawah lima tahun dengan keterlambatan bicara dan bahasa disertai gangguan pendengaran di RSUP Sanglah, Bali, Indonesia. Intisari Sains Medis 12(2): 563-567. D0I: 10.15562/ism.v12i2.1046

'Departemen IImu Kesehatan Telinga Hidung Tenggorokan-Kepala Leher (THT-KL), Fakultas Kedokteran, Universitas Udayana, RSUP Sanglah, Bali, Indonesia;

\section{*Korespondensi:}

Ni Made Ary Wisma Dewi;

Departemen IImu Kesehatan Telinga Hidung Tenggorokan-Kepala Leher (THT-KL), Fakultas Kedokteran, Universitas Udayana, RSUP Sanglah, Bali, Indonesia;

arywismadewi@gmail.com

\section{ABSTRAK}

Latar Belakang: Gangguan pendengaran merupakan salah satu faktor yang mempengaruhi perkembangan bicara dan bahasa pada anak terutama pada lima tahun pertama kehidupan. Deteksi gangguan pendengaran pada seorang anak dapat dilakukan dengan pemeriksaan Brainstem Evoked Response Audiometry (BERA) yang objektif. Penelitian ini bertujuan untuk melihat nilai gelombang BERA pada anak balita dengan keterlambatan bicara dan bahasa di Poliklinik THTKL RSUP Sanglah Denpasar.

Metode: Penelitian ini menggunakan rancangan penelitian deskriptif retrospektif dengan mengambil data sekunder dari catatan medis pasien keterlambatan bicara dan bahasa disertai gangguan pendengaran yang dilakukan pemeriksaan BERA. Sampel diambil dengan cara consecutive sampling. Analisis data pada penelitian ini terdiri dari analisis statistik deskriptif, uji T independen, dan one way ANOVA. Data dianalisis dengan SPSS versi 24 untuk Windows.

Hasil: Penelitian ini melibatkan 65 orang sebagai sampel. Berdasarkan jenis kelamin didapatkan jenis kelamin laki-laki $(76,9 \%)$ lebih banyak dari perempuan $(23,1 \%)$. Usia terbanyak pada usia 24-35 bulan (43,1\%). Gangguan pendengaran paling banyak yaitu SNHL Sedang pada telinga kanan (38,5\%), sedangkan pada telinga kiri SNHL Ringan (38,5\%). Rerata masa laten antar gelombang I-V pada telinga kiri balita lakilaki lebih panjang yaitu 4,96 ms dengan variasi 0,56 
ms, dibandingkan balita perempuan 4,59 ms dengan variasi 0,64 ms. Terdapat perbedaan bermakna rerata masa laten antar gelombang I-V telinga kiri antara balita laki-laki dan perempuan $(p=0,033)$.

Simpulan: Berdasarkan penelitian didapatkan bahwa masa laten absolut dan antar gelombang BERA pada

Kata kunci: BERA, Gangguan Pendengaran, Bicara, Bahasa.

Sitasi Artikel ini: Dewi, N.M.A.W., Wiranadha, I.M. 2021. Gelombang Brainstem Evoked Response Audiometry (BERA) pada anak di bawah lima tahun dengan keterlambatan bicara dan bahasa disertai gangguan pendengaran di RSUP Sanglah, Bali, Indonesia. Intisari Sains Medis 12(2): 563-567. D0I: 10.15562/ism.v12i2.1046

\section{PENDAHULUAN}

Pendengaran memegang peran dasar dan penting pada bahasa, bicara, dan perkembangan intelektual. Lima tahun pertama kehidupan seorang anak merupakan suatu masa yang menentukan untuk kehidupan anak selanjutnya. ${ }^{1}$ Prevalensi keterlambatan bicara pada anak usia 2-7 tahun di Amerika Serikat berkisar antara 2,3-19\%.2 Studi potong lintang di India mendapatkan prevalensi keterlambatan bicara dan bahasa sebanyak $27 \%$ pada anak-anak kurang dari 3 tahun. ${ }^{3}$ Studi di Indonesia, RS Dr. Kariadi Semarang pada tahun 2007 menemukan 100 anak-anak dengan keterlambatan bicara dari 436 anak-anak yang dilakukan pemeriksaan. ${ }^{4}$ Prevalensi keterlambatan bicara dan bahasa dari penelitian yang dilakukan di RSUP Sanglah Denpasar pada anak usia 2-4,5 tahun adalah 5-8\% dan usia $25-36$ bulan adalah $55,1 \%{ }^{5}$

Gangguan pendengaran merupakan salah satu faktor yang mempengaruhi perkembangan bicara dan bahasa pada anak. Studi di RS Dr. Hasan Sadikin Bandung, mendapatkan gangguan pendengaran merupakan penyebab paling sering dari keterlambatan bicara pada anak. ${ }^{6}$ Deteksi yang terlambat pada anak dapat mengakibatkan keterlambatan perkembangan bahasa yang ireversibel. Deteksi gangguan pendengaran pada seorang anak dapat dilakukan dengan pemeriksaan objektif yaitu dengan Brainstem Evoked Response Audiometry (BERA). ${ }^{7}$ Saat ini literatur di Indonesia yang memberikan informasi gambaran gelombang BERA terutama pada anak di bawah lima tahun (balita) dengan keterlambatan bicara dan bahasa masih sangat sedikit.
Berdasarkan uraian tersebut, maka dilakukan penelitian ini bertujuan untuk mengevaluasi gelombang Brainstem Evoked Response Audiometry (BERA) pada anak di bawah lima tahun dengan keterlambatan bicara dan bahasa disertai gangguan pendengaran di RSUP Sanglah, Bali, Indonesia.

\section{METODE}

Penelitian ini menggunakan rancangan penelitian deskriptif retrospektif dengan mengambil data sekunder dari catatan medis pasien keterlambatan bicara dan bahasa disertai gangguan pendengaran yang dilakukan pemeriksaan BERA di RSUP Sanglah Denpasar periode Januari hingga Agustus 2020. Penelitian dilakukan di Poliklinik THTKL RSUP Sanglah Denpasar pada bulan Oktober-November 2020. Populasi penelitian adalah semua pasien dengan keterlambatan bahasa dan bicara disertai gangguan pendengaran yang berobat ke Poliklinik THTKL RSUP Sanglah Denpasar.

Pengambilan sampel dilakukan dengan cara consecutive sampling. Teknik penentuan sampel ini yaitu, setiap data subjek yang didapatkan dari rekam medis memenuhi kriteria penelitian diikutsertakan dalam analisis data. Kriteria inklusi adalah semua pasien usia di bawah 5 tahun yang terdiagnosis dengan keterlambatan bicara dan bahasa disertai gangguan pendengaran. Kriteria eksklusi adalah pasien dengan keterlambatan bahasa dan bicara disertai gangguan pendengaran dengan data rekam medis yang tidak lengkap, usia di atas 5 tahun, dan atau kelainan telinga luar dan tengah. Analisis data pada penelitian ini terdiri dari analisis statistik deskriptif uji $\mathrm{T}$ independen dan oneway ANOVA dengan nilai $\mathrm{p}<0,05$ menunjukkan hasil yang bermakna. Analisis data menggunakan perangkat lunak IBM SPSS versi 24 untuk Windows.

\section{HASIL}

Penelitian ini melibatkan subjek 65 orang dengan karakteristik penelitian yang diamati meliputi, jenis kelamin, usia, serta jenis dan derajat gangguan pendengaran ditunjukkan pada Tabel 1. Karakteristik berdasarkan jenis kelamin didapatkan jenis kelamin laki-laki sebanyak 50 pasien atau $76,9 \%$ dan perempuan 15 pasien atau $23,1 \%$. Karakteristik usia didapatkan usia terbanyak pada usia 24-35 bulan sebanyak 28 pasien atau $43,1 \%$. Karakteristik jenis dan derajat gangguan pendengaran didapatkan paling banyak yaitu SNHL Sedang pada telinga kanan sebanyak 25 pasien atau $38,5 \%$, sedangkan pada telinga kiri didapatkan gangguan terbanyak yaitu SNHL Ringan sebanyak 25 pasien atau 38,5\% (Tabel 1).

Berdasarkan Tabel 2 didapatkan bahwa masa laten absolut dan antar gelombang BERA pada telinga kanan tidak ada perbedaan yang bermakna secara statistik pada balita laki-laki dan perempuan berdasarkan hasil uji $\mathrm{T}$ didapatkan nilai $p>0,05$. Namun, rerata masa laten antar gelombang I-V pada telinga kiri balita laki-laki lebih panjang yaitu $4,96 \mathrm{~ms}$ dengan variasi $0,56 \mathrm{~ms}$, dibandingkan balita perempuan 4,59 ms dengan variasi $0,64 \mathrm{~ms}$. Hasil uji $\mathrm{T}$ didapatkan $\mathrm{p}=0,033$, berarti secara statistik terdapat perbedaan bermakna rerata masa laten antar gelombang I-V pada balita laki-laki dengan perempuan.

Berdasarkan Tabel 3, didapatkan 
Tabel 1. Karakteristik subjek penelitian berdasarkan usia, jenis kelamin, dan gangguan pendengaran.

\begin{tabular}{lc}
\hline \multicolumn{1}{c}{ Karakteristik } & Total $(\mathbf{N}=\mathbf{6 5})$ \\
\hline Jenis Kelamin, $\mathrm{n}(\%)$ & $50(76,9)$ \\
Laki-Laki & $15(23,1)$ \\
Perempuan & \\
Kategori Usia (Bulan), n (\%) & $10(15,4)$ \\
$<12$ & $12(18,5)$ \\
$12-23$ & $28(43,1)$ \\
$24-35$ & $11(16,9)$ \\
$36-47$ & $4(6,2)$ \\
$48-59$ & \\
Gangguan Pendengaran & $18(27,7)$ \\
Telinga Kanan, n $(\%)$ & $25(38,5)$ \\
SNHL Ringan $(26-40 \mathrm{~dB})$ & $7(10,8)$ \\
SNHL Sedang (41-60 dB) & $15(23,1)$ \\
SNHL Berat $(61-80 \mathrm{~dB})$ & \\
SNHL Sangat Berat $(\geq 81 \mathrm{~dB})$ & $20(30,8)$ \\
Telinga Kiri, n $(\%)$ & $25(38,5)$ \\
Normal Hearing $(0-25 \mathrm{~dB})$ & $11(16,9)$ \\
SNHL Ringan $(26-40 \mathrm{~dB})$ & $3(4,6)$ \\
SNHL Sedang $(41-60 \mathrm{~dB})$ & $6(9,2)$ \\
SNHL Berat $(61-80 \mathrm{~dB})$ &
\end{tabular}

SNHL: Sensorineural Hearing Loss; dB: Desibel

Tabel 2. Masa laten (milidetik) gelombang BERA pada balita laki-laki dan perempuan.

\begin{tabular}{cccc}
\hline Masa Laten & $\begin{array}{c}\text { Laki-laki } \\
\text { (Rerata } \pm \text { SB })\end{array}$ & $\begin{array}{c}\text { Perempuan } \\
\text { (Rerata } \pm \text { SB) }\end{array}$ & p \\
\hline Telinga Kanan (ms) & & & \\
Gelombang I & $1,38( \pm 0,35)$ & $1,41( \pm 0,43)$ & 0,755 \\
Gelombang III & $3.80( \pm 0,55)$ & $3,76( \pm 0,82)$ & 0,823 \\
Gelombang V & $6,08( \pm 0,61)$ & $6,13( \pm 0,82)$ & 0,807 \\
Gelombang I-III & $2,42( \pm 0,47)$ & $2,32( \pm 0,67)$ & 0,547 \\
Gelombang III-V & $2,28( \pm 0,39)$ & $2,36( \pm 0,63)$ & 0,634 \\
Gelombang I-V & $4,73( \pm 0,62)$ & $4,71( \pm 0,74)$ & 0,935 \\
Telinga Kiri (ms) & & & \\
Gelombang I & $1,37( \pm 0,37)$ & $1,47( \pm 0,37)$ & 0,345 \\
Gelombang III & $3,85( \pm 0,61)$ & $3,67( \pm 0,49)$ & 0,278 \\
Gelombang V & $6,33( \pm 0,60)$ & $6,17( \pm 0,71)$ & 0,389 \\
Gelombang I-III & $2,48( \pm 0,50)$ & $2,26( \pm 0,35)$ & 0,121 \\
Gelombang III-V & $2,62( \pm 1,12)$ & $2,50( \pm 0,42)$ & 0,688 \\
Gelombang I-V & $4,96( \pm 0,56)$ & $4,59( \pm 0,64)$ & $0,033^{*}$ \\
\hline
\end{tabular}

$\mathrm{AD}=$ Auris Dekstra; $\mathrm{AS}=$ Auris Sinistra; ms: millisecond atau milidetik; SB: Simpang Baku; ${ }^{*} \mathrm{Uji}$ ANOVA dikatakan bermakna apabila nilai-p kurang dari 0,05

rerata masa laten absolut gelombang I pada telinga kanan berdasarkan kategori usia paling panjang pada kategori usia 36-47 bulan yaitu $1,66 \mathrm{~ms}$ dengan variasi 0,28 ms. Hasil uji ANOVA diperoleh $\mathrm{p}=0,005$ artinya secara statistik ada perbedaan yang bermakna rerata masa laten absolut gelombang I pada telinga kanan berdasarkan kategori usia (Tabel 3). Namun, masa laten absolut dan antar gelombang BERA pada telinga kiri tidak ada perbedaan yang bermakna secara statistik pada kategori usia berdasarkan hasil uji ANOVA diperoleh nilai $\mathrm{p}>0,05$ (Tabel 3).

\section{PEMBAHASAN}

BERA merupakan tes penting yang digunakan untuk menegakkan suatu tipe gangguan dengar, mengidentifikasi perubahan retrokoklear atau sistem saraf pusat, serta untuk menilai maturitas sistem auditori pada neonatus. ${ }^{7}$ Pemeriksaan BERA dapat menunjang gangguan yang terjadi pada anak dengan keterlambatan bicara dan bahasa.

Penelitianinimendapatkanjumlahanak laki-laki yang diperiksa pendengarannya lebih banyak dibandingkan dengan anak perempuan. Hal ini menunjukkan bahwa permasalahan gangguan dengar lebih banyak ditemukan pada anak laki-laki dibandingkan dengan perempuan pada pasien dengan keterlambatan bicara dan bahasa. Penelitian oleh Wijana et al., menunjukkan bahwa gangguan dengar lebih banyak dialami oleh anak laki-laki dibandingkan perempuan. ${ }^{1}$ Sedangkan penelitian oleh Sari SNL et al., menunjukkan anak-anak penderita keterlambatan bicara dengan gangguan pendengaran terbanyak adalah laki-laki $(65,9 \%){ }^{8}$

Berdasarkan usia pada penelitian ini didapatkan usia terbanyak adalah 2435 bulan. Penelitian oleh Gunawan LM et al., mendapatkan sebagian besar anak yang didapatkan dengan keterlambatan bicara dan bahasa disertai gangguan pendengaran berusia 24-35 bulan. ${ }^{6} \mathrm{Hal}$ ini menunjukkan bahwa orang tua tidak menyadari adanya gangguan pendengaran pada anak mereka yang mungkin diakibatkan oleh kurangnya kesadaran dan pengetahuan orang tua mengenai reaksi anak-anak mereka terhadap suara dan dampak pendengaran bagi anak. Apabila anak didiagnosis mengalami gangguan pendengaran sebelum usia 6 bulan, anak masih mempunyai kesempatan besar untuk dapat berbicara dan berkomunikasi secara optimal, apabila anak mendapatkan penatalaksanaan lebih dini. Studi yang dilakukan oleh Yoshinaga-Itano $\mathrm{C}$ et al., menyatakan identifikasi dan penatalaksanaan dini gangguan pendengaran permanen pada anak diketahui berdampak pada peningkatan perkembangan, anak dengan gangguan pendengaran yang mendapatkan intervensi sebelum usia 6 bulan mengalami peningkatan dalam bahasa pada usia 3 tahun. ${ }^{9}$

Gangguan pendengaran terbanyak pada penelitian ini yaitu SNHL Sedang pada telinga kanan dan SNHL Ringan pada telinga kiri. Hasil yang sama juga 
Tabel 3. Masa laten (milidetik) gelombang BERA pada balita berdasarkan usia

\begin{tabular}{|c|c|c|c|}
\hline Usia & Rerata & SB & $\mathbf{p}$ \\
\hline \multicolumn{4}{|c|}{ Gelombang I AD (ms) } \\
\hline$<12$ bulan & 1,11 & 0,25 & $0,005^{\star}$ \\
\hline $12-23$ bulan & 1,51 & 0,49 & \\
\hline $24-35$ bulan & 1,32 & 0,32 & \\
\hline $36-47$ bulan & 1,66 & 0,28 & \\
\hline $48-59$ bulan & 1,40 & 0,27 & \\
\hline \multicolumn{4}{|c|}{ Gelombang III AD (ms) } \\
\hline$<12$ bulan & 3,66 & 0,72 & 0,713 \\
\hline $12-23$ bulan & 3,96 & 0,75 & \\
\hline $24-35$ bulan & 3,71 & 0,58 & \\
\hline $36-47$ bulan & 3,92 & 0,49 & \\
\hline $48-59$ bulan & 3,84 & 0,62 & \\
\hline \multicolumn{4}{|c|}{ Gelombang V AD (ms) } \\
\hline$<12$ bulan & 6,12 & 0,81 & 0,983 \\
\hline $12-23$ bulan & 6,05 & 0,68 & \\
\hline $24-35$ bulan & 6,09 & 0,66 & \\
\hline $36-47$ bulan & 6,17 & 0,61 & \\
\hline $48-59$ bulan & 5,96 & 0,57 & \\
\hline \multicolumn{4}{|c|}{ Gelombang I-III AD (ms) } \\
\hline$<12$ bulan & 2,56 & 0,66 & 0,762 \\
\hline $12-23$ bulan & 2,41 & 0,51 & \\
\hline $24-35$ bulan & 2,38 & 0,50 & \\
\hline $36-47$ bulan & 2,25 & 0,37 & \\
\hline 48 - 59 bulan & 2,44 & 0,73 & \\
\hline \multicolumn{4}{|c|}{ Gelombang III-V AD (ms) } \\
\hline$<12$ bulan & 2,46 & 0,59 & 0,298 \\
\hline $12-23$ bulan & 2,08 & 0,25 & \\
\hline $24-35$ bulan & 2,35 & 0,46 & \\
\hline $36-47$ bulan & 2,33 & 0,50 & \\
\hline 48 - 59 bulan & 2,12 & 0,12 & \\
\hline \multicolumn{4}{|c|}{ Gelombang I-V AD (ms) } \\
\hline$<12$ bulan & 5,01 & 0,73 & 0,472 \\
\hline $12-23$ bulan & 4,53 & 0,45 & \\
\hline $24-35$ bulan & 4,76 & 0,62 & \\
\hline $36-47$ bulan & 4,63 & 0,80 & \\
\hline $48-59$ bulan & 4,56 & 0,69 & \\
\hline \multicolumn{4}{|c|}{ Gelombang I AS (ms) } \\
\hline$<12$ bulan & 1,23 & 0,43 & 0,207 \\
\hline $12-23$ bulan & 1,29 & 0,40 & \\
\hline $24-35$ bulan & 1,41 & 0,30 & \\
\hline $36-47$ bulan & 1,59 & 0,44 & \\
\hline 48 - 59 bulan & 1,42 & 0,21 & \\
\hline \multicolumn{4}{|c|}{ Gelombang III AS (ms) } \\
\hline$<12$ bulan & 3,46 & 0,53 & 0,085 \\
\hline $12-23$ bulan & 3,83 & 0,56 & \\
\hline $24-35$ bulan & 3,76 & 0,59 & \\
\hline $36-47$ bulan & 4,13 & 0,50 & \\
\hline $48-59$ bulan & 4,12 & 0,60 & \\
\hline \multicolumn{4}{|c|}{ Gelombang V AS (ms) } \\
\hline$<12$ bulan & 6,00 & 0,53 & 0,345 \\
\hline $12-23$ bulan & 6,30 & 0,66 & \\
\hline
\end{tabular}

didapatkan pada penelitian oleh Gunawan LM et al., yaitu gangguan pendengaran terbanyak pada anak dengan SNHL dibandingkan gangguan pendengaran CHL. ${ }^{6}$ Penelitian oleh Halliday LF et al., mendapatkan anak dengan SNHL ringan sampai sedang lebih buruk secara bermakna dalam bicara dan bahasa dibandingkan dengan anak yang seumuran. ${ }^{10}$

Data yang diperoleh dari penelitian ini juga memperlihatkan tidak terdapat perbedaan yang bermakna rerata masa laten absolut dan masa laten antar gelombang BERA telinga kanan, baik pada balita laki-laki maupun balita perempuan. Namun, didapatkan perbedaan bermakna rerata masa laten antar gelombang I-V pada telinga kiri balita laki-laki dengan perempuan, masa laten pada laki-laki lebih lambat dibandingkan perempuan. Penelitian oleh Esteves MC et al., menunjukkan tidak terdapat perbedaan bermakna masa laten antar gelombang I-V pada telinga kiri laki-laki dan perempuan, perbedaan bermakna ditemukan pada masa laten antar gelombang I-V dan gelombang $\mathrm{V}$ pada telinga kanan balita laki-laki dengan perempuan. ${ }^{11}$

Masa laten gelombang BERA berdasarkan kelompok usia pada penelitian ini didapatkan perbedaan yang bermakna pada masa laten absolut gelombang I pada telinga kanan berdasarkan kelompok usia dengan masa laten absolut terpanjang pada kelompok usia 36-47 bulan. Penelitian oleh Wijana et al., mendapatkan kelompok usia 0-1 tahun memiliki masa laten absolut dan masa laten antar gelombang BERA yang lebih panjang daripada kelompok usia di atasnya, namun tidak terdapat perbedaan yang bermakna pada gelombang I berdasarkan kelompok usia. ${ }^{1}$ Kemungkinan hal tersebut berhubungan dengan proses maturitas jaras pendengaran. Gelombang I mempunyai masa perkembangan yang paling singkat, gelombang ini mencapai masa laten yang sama dengan dewasa pada usia sekitar 2-3 bulan, sedangkan gelombang $\mathrm{V}$ mempunyai masa perkembangan yang paling lama, gelombang ini mencapai masa laten yang sama dengan dewasa pada usia sekitar dua tahun kehidupan. ${ }^{12,13}$ 


\begin{tabular}{|c|c|c|c|}
\hline Usia & Rerata & SB & $\mathbf{p}$ \\
\hline $24-35$ bulan & 6,27 & 0,69 & \\
\hline $36-47$ bulan & 6,52 & 0,51 & \\
\hline 48 - 59 bulan & 6,59 & 0,27 & \\
\hline \multicolumn{4}{|c|}{ Gelombang I-III AS (ms) } \\
\hline$<12$ bulan & 2,33 & 0,58 & 0,500 \\
\hline $12-23$ bulan & 2,54 & 0,47 & \\
\hline $24-35$ bulan & 2,35 & 0,48 & \\
\hline $36-47$ bulan & 2,52 & 0,31 & \\
\hline 48 - 59 bulan & 2,70 & 0,63 & \\
\hline \multicolumn{4}{|c|}{ Gelombang III-V AS (ms) } \\
\hline$<12$ bulan & 3,17 & 2,25 & 0,410 \\
\hline $12-23$ bulan & 2,47 & 0,43 & \\
\hline $24-35$ bulan & 2,54 & 0,62 & \\
\hline $36-47$ bulan & 2,40 & 0,37 & \\
\hline $48-59$ bulan & 2,47 & 0,40 & \\
\hline \multicolumn{4}{|c|}{ Gelombang I-V AS (ms) } \\
\hline$<12$ bulan & 4,61 & 0,76 & 0,460 \\
\hline $12-23$ bulan & 5,01 & 0,59 & \\
\hline $24-35$ bulan & 4,86 & 0,60 & \\
\hline $36-47$ bulan & 4,92 & 0,41 & \\
\hline $48-59$ bulan & 5,17 & 0,43 & \\
\hline
\end{tabular}

$\mathrm{AD}=$ Auris Dekstra; $\mathrm{AS}=$ Auris Sinistra; ms: millisecond atau milidetik; SB: Simpang Baku; ${ }^{\star} \mathrm{Uji}$ ANOVA dikatakan bermakna apabila nilai-p kurang dari 0,05

\section{SIMPULAN}

Pendengaran merupakan salah satu faktor yang berkontribusi dalam perkembangan bicara dan bahasa pada anak. Berbagai pemeriksaan pendengaran dapat dilakukan untuk mendeteksi adanya gangguan pendengaran. Pemeriksaan BERA merupakan suatu pemeriksaan yang objektif. Deteksi dini gangguan pendengaran sangat penting dalam memaksimalkan perkembangan bicara dan bahasa anak. Program skrining pendengaran, pelaporan, dan pencatatan perlu ditingkatkan, sehingga anak dengan gangguan pendengaran terdeteksi dan diintervensi sejak awal.

\section{KONFLIK KEPENTINGAN}

Tidak terdapat konflik kepentingan dalam penulisan laporan penelitian ini.

\section{ETIKA PENELITIAN}

Penelitian ini sudah disetujui oleh Komisi Etik Penelitian FK UNUD/ RSUP Sanglah yang telah melakukan telaah proposal dengan nomor NO:1814/
UN14.2.2.VII.14/LT/2020.

\section{PENDANAAN}

Tidak ada.

\section{KONTRIBUSI PENULIS}

Seluruh penulis memiliki kontribusi yang sama dalam penyusunan laporan penelitian ini baik dari tahap penyusunan kerangka konsep, pengambilan data, analisis data, hingga penyusunan draft publikasi dalam bentuk laporan penelitian.

\section{UCAPAN TERIMA KASIH}

Penulis mengucapkan terima kasih kepada divisi Neurootologi Departemen/ KSM Ilmu Kesehatan THTKL Fakultas Kedokteran Universitas Udayana/ RSUP Sanglah Denpasar selama proses pendidikan maupun penulisan laporan penelitian ini.

\section{DAFTAR PUSTAKA}

1. Wijana, Syamsuddin A, Dewi YA. Gelombang Auditory Brainstem Response (ABR) pada anak di bawah lima tahun. Majalah Kedokteran Bandung. 2014;46(3):183-188.

2. McLaughlin MR. Speech and language delay in children. Am Fam Physician. 2011;83(10):11831188.

3. Mondal N, Bhat BV, Plakkal N, Thulasingam M, Ayajan P, Poorna DR. Prevalence and risk factors of speech and language delay in children less than three years of age. J Compr Ped. 2016;7(2):e33173.

4. Tan S, Mangunatmadja I, Wiguna T. Risk factors for delayed speech in children aged 1-2 years. Paediatricia Indonesiana. 2019;59(2):5562.

5. Beyeng R, Soetjiningsih, Windiani T. Prevalensi dan karakteristik keterlambatan bicara pada anak prasekolah di TPA Werdhi Kumara I dengan early language milestone scale- 2 . Jurnal Ilmu Kesehatan Anak. 2012;1(1):12-17.

6. Gunawan LM, Wijana, Pratiwi YS. OtoAcoustic Emission and Auditory Brainstem Response profile in children with speech delay at Dr. Hasan Sadikin General Hospital Bandung. Althea Medical Journal. 2016;3(2):265-268.

7. Giroux AP, Pratt LW. Brainstem evoked response audiometry. Ann Otol Rhinol Laryngol. 1983;92(2 Pt 1):183-186.

8. Sari SNL, Memy YD, Ghanie A. Angka kejadian delayed speech disertai gangguan pendengaran pada anak yang menjalani pemeriksaan pendengaran di Bagian Neurootologi IKTHTKL RSUP Dr.Moh. Hoesin. Jurnal Kedokteran dan Kesehatan. 2015;2(1):121-127.

9. Yoshinaga-Itano C, Sedey AL, Wiggin M, Chung W. Early Hearing Detection and Vocabulary of Children With Hearing Loss. Pediatrics. 2017;140(2):e20162964.

10. Halliday LF, Tuomainen O, Rosen S. Language Development and Impairment in Children With Mild to Moderate Sensorineural Hearing Loss. J Speech Lang Hear Res. 2017;60(6):15511567.

11. Esteves MC, Dell' Aringa AH, Arruda GV, Dell' Aringa AR, Nardi JC. Brainstem evoked response audiometry in normal hearing subjects. Braz J Otorhinolaryngol. 2009;75(3):420-425.

12. Robert B, McNerney K. Introduction to Auditory Evoked Potentials. In: Katz J, [Editor]. Handbook of Clinical Audiology. Baltimore: Lippincott Williams \& Wilkins; 2009: 222-41.

13. Bahrami MA, Ansari A, Chama-Ara, Bahrami E, Bahrami S, Bahrami MN, et al. Neutrophil-tolymphocyte ratio and platelet-to- lymphocyte ratio as novel markers for diagnosis of sudden sensorineural hearing loss: a systematic review and meta-analysis. Bali Medical Journal. 2016;5(2):197-201.

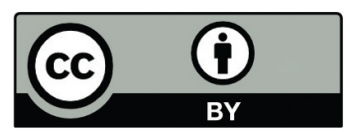

This work is licensed under a Creative Commons Attribution 